\title{
Gifted underachievement: The causes of gifted underachievement, and interventions to reverse this pattern
}

\author{
JESSY WU
}

\section{Abstract}

Giftedness is generally seen as the basis of superior academic performance. Therefore, the spectre of the gifted underachiever leaves educators scratching their heads. Despite being widely observed-a Victorian inquiry found that up to 50 per cent of gifted students do not perform at the level of which they are capable - the underlying causes of gifted underachievement are not well understood. In this article, I integrate evidence collected from interviews and from a literature review to devise a schematic for understanding gifted underachievement. I argue that giftedness is distinct from the ability to achieve. Instead, the development of gifts into talents is a continuous process, which can only occur if certain intrapersonal and environmental catalysts are present. With this understanding, I evaluate interventions schools use to reverse this trend, and analyse why certain elements of the interventions are particularly effective. I find motivation, the influence of peers and selfesteem to be particularly important catalysts. Following this, I make several recommendations as to how we can optimise learning environments to ensure these catalysts are present.

\section{Introduction}

In recent years, Australia has invested substantially in gifted and talented (G\&T) education programs for academically able children. This investment reflects strong parental interest in special education settings for capable students (Craven, Marsh $\&$ Print, 2000). Despite this investment, a large number of gifted students do not achieve at the level of which they are capable. The Victorian inquiry into the education of G\&T students estimated that up to 50 per cent of gifted students underachieve (Parliament of Victoria Education and Training Committee, 2012, p. 6), while a Senate committee estimated that as many as 40 per cent of gifted students leave school before the end of Year 12 (p. 6). 
The inquiry concludes that gifted underachievement 'is not well understood' (p. 6). Research in the area has concentrated on documenting symptoms of underachievement, while comparatively little has been done to understand the underlying causes of underachievement, or to design interventions that reverse underachievement by tackling its underlying causes. This article will contribute to the literature by examining the underlying causes of underachievement, and evaluating the efficacy of interventions designed to reverse this trend.

\section{Methodology}

For this article, I interviewed three teachers about the G\&T program at their school. In particular, I asked them to comment on patterns of underachievement they observed in G\&T students, and to describe strategies they used to support these students. The interviews were loosely structured, and the interviewee was allowed to direct the conversation.

To arrange these interviews, I reached out to more than 10 schools, including public, private, religious, single-sex and Steiner schools. I had a reasonable response rate; however, none of the respondents were from public schools. I chose to interview teachers from three schools, including a top performing single-sex school (Canberra Girls Grammar School [CGGS]), a religious co-educational school (Trinity Christian School), and a co-educational Steiner school (Orana Steiner School).

I chose these three schools because they represented diversity in educational pedagogy. However, this selection is not representative of all ACT schools-all three are private, and rank in the top 30 per cent of ACT schools by the Index of Community Socio-Educational Advantage score. These schools have more resources to expend on G\&T education, and therefore the strategies used to reverse underachievement at these schools may not be financially viable at other schools.

In this article, I integrate the qualitative evidence collected in these interviews with evidence collected from a review of the existing literature on this subject.

\section{Definitions}

\section{Giftedness}

Giftedness is sometimes defined as being two or more standard deviations above the mean on a measure of general intelligence, which places them in the top 2 per cent of the population. However, many scholars have renounced this definition in favour of a more dynamic one (Renzulli, 1982). In this article, I also reject this stagnant definition-how well a student performs on an assessment of general intelligence 
may be affected by how familiar they are with the kinds of questions asked, or how accustomed they are to working under exam conditions. Furthermore, many of the schools I use as case studies in this article do not subject their students to assessments of general intelligence. Instead, I will adopt a fluid definition of giftedness, based on the definition of giftedness used by the teachers in charge of G\&T education at their respective schools.

\section{Underachievement}

Underachievement is diagnosed and quantified using highly variable and sometimes subjective methods. Following a noted scholar in the field, I define the gifted underachiever 'as a student who achieves highly in tests of general aptitude and/ or otherwise demonstrates potential for well above-average academic performance, however achieves below-average results as assessed by test scores, grades, and teacher observation' (Reis \& McCoach, 2000). This describes a student for whom there is a large discrepancy between their academic potential and their school performance.

In the schools I examined, gifted underachievers are identified by their classroom teacher. Teachers are instructed to look for students who seem capable, but are disconnected from their learning. These students may offhandedly make perceptive comments, have an 'out there' sense of humour, or occasionally produce work of exceptional quality-but do not consistently apply their intelligence to their learning.

\section{Causes of gifted underachievement}

This section will explain why the gifted underachieve. In order to tackle this immense question, we must first interrogate its assumptions. Embedded within this question is the assumption that those who are gifted ought to achieve academically, regardless of whether necessary provisions have been made to support them. I will deconstruct this assumption, and argue that the process of talent development is only possible when certain intrapersonal and environmental catalysts are present in a child's education.

Scholars Françoys Gagné and Joseph Renzulli, who played a significant role in gifted and talented scholarship, have developed models that help us to understand why superior natural ability does not always precipitate superior academic performance (Gagné, 1997). They suggest that natural aptitude is necessary but not sufficient for superior academic achievement (Renzulli, 1982). They identify motivation, task commitment and creativity as examples of important catalysts, which sustain the student through obstacles, boredom and failure (Gagné, 1997). 
The process can be assisted or hindered by a number of factors, including hereditary predispositions, acquired styles of behaviour, the influence of significant others, and significant events (Gagné, 1997). This analysis explains why underachievement occurs: 'if the catalysts or the developmental process are missing, weak, ineffective or not meeting the student's needs over a period of time, gifts will not fully develop into talents, thus causing underachievement' (Namadgi School, 2016).

In order to test this hypothesis, I will analyse two instances of gifted underachievement. My first example is a trend identified by the Program for International Student Assessment (PISA) in 2012. PISA is a worldwide study of 15-year-old students' scholastic performance in mathematics, science and reading. PISA found that boys were generally outperforming girls in mathematics, and nowhere was the disparity more pronounced than among the highest performing students. In the large majority of countries, high-performing girls were doing worse in mathematics compared to boys; in no countries did girls outperform boys at the highest level (OECD, 2015, p. 14).

Given that research has shown there are no innate differences in natural aptitude between boys and girls (p. 64), I suggest this trend is an example of underachievement. To understand this trend, PISA examined some of the 'intangibles that could have an effect on learning, such as drive, motivation, and self-concept' (p. 68).

Some of the 'starkest differences between boys and girls were revealed when students expressed their feelings about their own abilities' (p. 68). Girls had less belief in their own abilities and were plagued with greater anxieties towards maths-even though they perform just as well (p. 68). The study also revealed a strong correlation between self-esteem and academic performance, and 'at every level, girls tended to have much lower levels of self-esteem' (p. 31).

Self-esteem is one of the intrapersonal catalysts identified by Gagné (1997). The literature suggests several reasons why self-esteem is an important catalyst for talent development. When students have higher levels of self-esteem, they are able to recognise that failing does not make them a failure. 'They give themselves the freedom to fail —and thereby engage in a process of trial and error that is central to acquiring skills in mathematics and in science' (OECD, 2015, p. 14). Self-esteem also gives students the confidence to persevere, and to motivate themselves in the face of challenges and setbacks (Bandura, 1977). Researchers have noted that low self-esteem and low self-efficacy is commonly observed in gifted underachievers (Hoffman, Wasson \& Christianson, 1985). 
The teacher at Orana expressed sentiments that corroborate this theory. She remarked that students who were anxious about failing were less likely to challenge themselves, and would shy away from attempting activities where success was not guaranteed. Conversely, students who had high self-esteem were able to shrug off their failures, reflect upon their learning and learn from their mistakes.

My second example is gifted underachievement at Trinity Christian School. This evidence was collected in an interview with the teacher in charge of G\&T education at Trinity. In the interview, I asked the teacher to describe behaviours he commonly observed in underachieving gifted students.

He reported that gifted underachievers were often disconnected from their learning. This disconnection could manifest in several ways_-some students are consistently oppositional or obstructive in class, while others are withdrawn and seem to take no interest in classroom proceedings. When questioned on why gifted students behaved in this manner, he suggested that students could be responding to pressure to be accepted by their peers - they may not want to stand out, for fear of disapproval. Feeling like a fish out of water can be difficult for an adolescent child. This observation speaks to a well-documented phenomenon-many gifted children do not relate well to their age peers, and relate better to peers that are their intellectual equals. This observation is supported by research, which also suggests that this pressure is even stronger for those students who come from minority backgrounds (Diaz, 1998).

Moreover, he observed that gifted students can be calculating. They are aware that demonstrations of giftedness may draw unwanted attention from the teacher, and result in them being given extra work to do. This work may not be work that the student enjoys and, in many classes, simply take the form of extra worksheets. This causes the student to refrain from displaying their giftedness.

To ground these observations in Gagnés theoretical framework, I suggest both examples highlight the role intrapersonal and environmental catalysts play in the process of talent development. These observations support the hypothesis that selfesteem, the influence of peers and the absence of programs that stimulate the child can profoundly impact the process of talent development.

\section{Interventions}

This section examines three interventions designed to reverse underachievement: a Type III creative project, extracurricular enrichment programs and assorted classroom strategies. 


\section{Type III enrichment}

To begin, I will appraise an intervention conducted in America that used Type III enrichment projects to reverse the pattern of underachievement.

Type III enrichment is an inductive form of learning where students are cast in the role of first-hand inquirers rather than mere lesson-learners (Renzulli, 1977, 2012). This form of learning has three key characteristics: the topic is personalised, students are using methods that approximate those used by practising professionals and the finished product is intended to have an impact on a particular audience (Baum, Renzulli \& Hébert, 1995).

In this intervention, students are guided through a Type III project by their teacher. The intervention allowed students to undertake projects that interested them. It 'represented an opportunity to choose a topic of interest and create new knowledge in their preferred style of learning' (p. 230). Some students designed solar cars, while others wrote a choose-your-own-adventure novel (p. 232). Teachers worked with students to determine the problem to be investigated and to set up a management plan (p. 227). Teachers also provided necessary resources and guidance, and helped students to 'share their completed investigation with interested audiences' (p. 227).

The study deemed the intervention successful. Over the course of the year, 82 per cent of students made positive gains across their subject areas, and the majority were no longer underachieving at the end of the intervention: ' 11 of the 17 participants showed improved achievement; 13 of the 17 students appeared to exert more effort within their classes; and 4 of the 17 students showed marked improvement in their classroom behaviour' (p. 224).

\section{Extracurricular enrichment programs}

In this section, I examine extracurricular enrichment programs used by schools to support G\&T students who are underachieving.

In two of the schools I researched, gifted underachievers are invited to participate in extracurricular enrichment programs such as the Maths Olympiad and the da Vinci Decathlon. These programs are characterised by challenging tasks that require lateral thinking, environments where students are surrounded by other capable and intelligent peers, and where the concerted application of effort and intelligence is celebrated. One G\&T coordinator remarked that a defining feature of these interventions was the experience of walking into a room comprising hundreds of other capable and intelligent students.

These extracurricular activities are more conceptually challenging than classroom work, and often combine knowledge from a number of disciplines. For example, a challenge in the 2015 da Vinci Decathlon was to compose an original poem and 
an integrated work of art that represented the places that bore significance to the life of a famous individual. The poem and the artwork had to be closely integrated, but could otherwise take any form (NSW State da Vinci Decathlon, 2015).

The challenges featured in these programs are rarely pragmatic or vocational. Instead, they place an emphasis on teaching students to apply metacognition and to create knowledge. One G\&T coordinator observed that students with natural aptitude seemed to warm to this idea, and even those who are normally disconnected from their learning seemed to display interest in these activities.

Students who participate in these programs are acknowledged and celebrated in front of the entire community. At assembly, the principal will congratulate the student for being an elite scholar, and for representing the school at a statewide competition. This gesture is intended to build a profile for the student-to make them feel like a significant and valued member of the community.

\section{Classroom strategies}

In this section, I describe three strategies used by teachers to support and motivate underachieving G\&T students from within the classroom.

At Orana, teachers work hard to ensure the classroom is a secure learning environment where students feel affirmed and supported by their peers. This endeavour is abetted by the school's policy of keeping students with the same classmates for seven years. This means the students have shared many formative experiences and have grown to accept one another. The teacher also promotes tolerance by modelling good behaviour, having a firm policy against putting each other down, and creating opportunities for students to showcase their individuality.

At CGGS, teachers set clear expectations for underperforming students, and explicitly praise them when they meet those expectations. Moreover, teachers expressly praise the effort exerted by the students, rather than the result achieved.

At Trinity, underachievers are invited to a meeting with a teacher or a counsellor. The teacher helps the student come to terms with their natural talents and see those talents as something they can take pride in. The teacher also encourages the student to verbalise any difficulties they are having, including whether peer pressure is preventing them from expressing their talents in class. A secondary aim of this process is to build a relationship of trust between the student and an adult in the school. A trusted teacher is not only someone who understands the student, but also someone who believes in who the student can become. 


\section{Evaluation of interventions}

In this section, I will evaluate the interventions described in the previous section, in terms of how they interact with three underlying causes of underachievement. These are:

- a lack of motivation

- susceptibility to peer pressure

- a lack of self-esteem.

I have chosen these underlying causes because they are featured in the theoretical framework of Gagné and Renzulli, and because they were consistently identified by the educators I interviewed. I will compare and contrast the interventions in order to understand what makes a successful intervention.

\section{Motivation}

Motivation is an important catalyst for talent development, and researchers have long observed that underachievers lack motivation. Whether a student is motivated is determined by a complex network of influences-including their early childhood education, their family and their peers. This means school-based interventions are constrained in their ability to motivate a student. However, I suggest interventions are able to simulate a state of being motivated, which could catalyse the process of talent development. In this section, I will examine how interventions attempt to simulate a state of being motivated, and evaluate the results.

The state of being motivated has been called optimal motivation. This refers to an experience where students become absorbed in the task at hand. 'They are clearly focused and totally involved; time seems to fly by and their exertions seem effortless' (Rea, 2000, p. 192). This experience demonstrates the relationship between rewarding experiences and the concerted application of effort over a sustained period of time (p. 192). Students are most likely to experience optimal motivation when their interests are aroused. Other consistently identified elements of optimal motivation include 'clear goals, immediate feedback, a challenging activity that requires the application of skills, concentration on the task at hand, and a sense of control over actions' (Csikszentmihalyi, Rathunde \& Whalen, 1993, p. 14).

This phenomenon can help us to understand why the Type III enrichment was successful. The enrichment contained many of the elements described above, combining the opportunity to pursue an area of interest with access to supervisors who could provide them with scaffolding techniques, help them to master methods used by practising professionals and give them feedback on their progress. Moreover, students who persevered with a project over the course of an entire year gained an 
appreciation for the relationship between effort and outcomes. The relationship is underlined when students present their project to an interested audience, and come to understand the real-world value of the work they do in class.

This analysis brings nuance to the commonplace assumption that students will be motivated if they are working on something that interests them. I argue the other elements of optimal motivation—such as clear goals, immediate feedback and a sense of control over actions-are equally important for talent development. This theory is corroborated by the classroom teacher at Orana. She remarked that underachieving students were unable to independently pursue topics that interested them, but responded better to structured, teacher-guided extension activities. This included asking students to work steadily through a checklist, or to devise a given number of questions that extend on the subject covered in class. This suggests students need guidance from their teachers to pursue their interests.

The Type III enrichment also taught students how to be optimally motivated in their other classes. For students with 'underdeveloped learning or organisational skills, completing this intervention helped them become aware of strategies that could facilitate learning' (Baum et al., 1995). The teacher would suggest strategies, or help the student to invent their own ways of solving the problem. Students were then able to apply these strategies to other classes.

I conclude that encouraging a student to pursue an area of interest is necessary but not sufficient for inducing a state of optimal motivation. In order to induce this state, I recommend that educators use scaffolding techniques to guide the student, provide constant feedback and ensure the student has a sense of control over the direction of the project.

\section{The influence of peers}

Research has consistently shown that gifted students feel pressured to fit in with their peers (Betts \& Neihart, 1988). This can cause them to hide their talents for fear of disapproval or ostracism-in some peer groups, the expression of intelligence is associated with shame. My research suggests that peer pressure often prevents gifted students from feeling secure within their learning environment, thus hindering the process of talent development. In this section, I will examine how the interventions harness the influence of peers in a productive manner, and then evaluate the results.

First, I will discuss the extracurricular enrichment programs at Trinity. These programs place gifted students in a group comprising other capable students, who enjoy being challenged and value academic achievement. According to the coordinator, this intervention has been successful at reversing underachievement. The students involved in the program learn about themselves: they learn that the expression of their gifts is good and will get them somewhere; they learn that they 
have intellectual peers; they become excited about their gifts and what it can mean for them. Students come away with a sense of pride, knowing they have participated in an activity they were specially selected for and they have done well.

Importantly, the coordinator reported that attempts to enrich the same underachieving students within the classroom, through the provision of challenging activities, were comparatively unsuccessful. While this could be attributed to a failure to provide appropriately challenging work, it could also be affected by the student's unwillingness to be singled out, and made to look different in front of peers who do not value academic excellence. In contrast, enrichment programs allow students to express their interest in an activity in a context where interest is valued and praised, rather than ridiculed. Furthermore, intellectual peers may become positive role models for underachieving students, as examples of fellow students who are rewarded socially for academic success.

To unpack the strengths and weaknesses of this intervention, I will compare and contrast these programs to classroom strategies used by teachers at Orana. Both strategies attempt to surround students with peers who will accept and embrace their giftedness and their individuality—but where Trinity attempts to expose gifted students to positive peer influences outside the classroom, Orana attempts to create a supportive learning environment within the classroom. The teacher at Orana believes this environment plays an important role in empowering some students to express themselves creatively, and to present their work in ways that reflect their unique personality. Despite this, there are capable students who continue to underachieve. Chronic underachievers remain uninterested and unmotivated when given opportunities to explore and showcase their interests. In fact, they seek attention and approval from their classmates in other ways, such as by disrupting the class or providing a distraction for their peers.

I argue both interventions have their strengths and weaknesses. Orana allows students to explore their interests and to express themselves unconventionally, free from the pressure to conform to a narrow conception of academic achievement. However, because academic excellence is not necessarily highly valued by all members of the peer group, some students may find it easier to seek approval from their peers in other ways, including those that detract from their learning.

Conversely, Trinity attempts to harness the influence of intelligent peers to encourage underachievers to pursue academic excellence. These peers showcase the social value of academic achievement, and create pressure to conform to the group by rising to the challenge of the task at hand. However, in this environment, acceptance and recognition by peers may become contingent on achievement. This means that those who are unable to achieve may become disillusioned and disengaged-this experience may exacerbate their feelings of loneliness and ostracism, thus further hindering the process of talent development. 
I suggest the optimal intervention can combine elements of both strategies. This intervention could harness the influence of peers to support and motivate the underachiever, while ensuring the student feels unconditionally accepted. I suggest Trinity's strategy of celebrating the student's achievements in front of their peers, thus making gifted students feel valued by their school community, may go some way towards creating this optimal environment.

\section{Self-esteem}

As previously mentioned, low self-esteem can be an underlying cause of underachievement (Gagné, 1997). Having high self-esteem allows the student to disassociate failing at an individual task from being a failure, thus giving them the confidence to experiment and to attempt tasks that challenge them. In this section, I will examine how the interventions attempt to improve the confidence of underachieving students, and then evaluate the results of doing so.

I begin by discussing the classroom strategy used at CGGS. In this strategy, teachers set clear expectations for underperforming students, and explicitly praise them when they met those expectations. Moreover, teachers expressly praise the effort exerted by the students, rather than the result achieved.

This form of praise is a counterpoint to the excessive praise that adults sometimes heap on gifted children. Many children interpret excessive praise as an expectation to be perfect, and feel demoralised when they cannot live up to these expectations. Instead, praising students for meeting realistic expectations affirms their achievements, eases their anxiety and relieves the pressure to live up to the impossible standards they have imposed upon themselves.

Moreover, this praise also improves the student's academic self-concept. Students evaluate their performance against external metrics-they compare their performance to that of their peers and siblings, to their past performance and to their goals. Praising specific achievements helps the student to understand success in terms of meeting specific goals. This addresses the phenomenon identified by the PISA study, where girls try to meet impossible standards, and are devastated when they fall short (OECD, 2015). This strategy gives students a realistic goal to aim for, and affirms them when they succeed.

Now I will compare this strategy with the counselling program at Trinity. This program facilitates relationships between teachers and students that seem analogous to those between mentors and mentees. Both are supportive relationships where the mentor provides support, guidance and concrete assistance to the mentee during a difficult time. A longitudinal study of mentor relationships has found 
that mentors have a significant impact on the achievement of gifted individuals (Torrance, 1980, 1984). Research suggests mentors help students to construct and to realise the image of themselves they have for their future (Levinson et al., 1978).

For the underachieving student, a mentor who believes in them and has concrete expectations of them can be instrumental in reversing their pattern of underachievement. This comparison highlights the role educators can have in raising a student's self-esteem. Having clear expectations for students can not only help those who are anxious about their performance, it can also help underachieving students to construct a positive image of themselves and their abilities.

\section{Conclusion}

This article began by asking why the gifted underachieve. However, this question is misguided because it assumes that giftedness and achievement are mutually interchangeable. Instead, this article has presented evidence to show that the development of gifts into talents is an ongoing process, which must be catalysed by an education.

This article has examined strategies that educators (both locally and internationally) use to reverse patterns of underachievement in G\&T students. It has deconstructed these strategies and made an effort to analyse their relation to the underlying causes of gifted underachievement. Comparing and contrasting different strategies has been a fruitful methodology, as it has allowed me to isolate the elements of strategies that are effective, and to extrapolate from these examples some general lessons about how to reverse patterns of underachievement.

To conclude, I recommend that education departments devise a strategy that combines the key elements of each intervention, as identified by this article. This strategy would provide guidance to teachers and G\&T coordinators, and go some way towards addressing the concern that teachers are not adequately trained to identify and support G\&T students, particularly those who are underachieving.

\section{Bibliography}

Bandura, A. (1977). Social Learning Theory. New York, NY: General Learning Press.

Baum, S.M., Renzulli, J.S. \& Hébert, T.P. (1995). 'Reversing Underachievement: Creative Productivity as a Systematic Intervention'. Gifted Child Quarterly, 39, 224-235. doi.org/10.1177/001698629503900406

Betts, G. \& Neihart, M. (1988). 'Profiles of the Gifted and Talented'. Gifted Child Quarterly, 32(2), 248-253. doi.org/10.1177/001698628803200202 
Craven, R., Marsh, H. \& Print, M. (2000). 'Gifted, Streamed and MixedAbility Programs for Gifted Students: Impact on Self-Concept, Motivation, and Achievement'. Australian Journal of Education, 44(1), 51-75. doi.org/ $10.1177 / 000494410004400106$

Csikszentmihalyi, M., Rathunde, K. \& Whalen, S. (1993). Talented Teenagers: The Roots of Success and Failure. New York: Cambridge University Press.

Diaz, E.I. (1998). 'Perceived Factors Influencing the Academic Underachievement of Talented Students of Puerto Rican Descent'. Gifted Child Quarterly, 42, 105122. doi.org/10.1177/001698629804200205

Gagné, F. (1997). 'Differential Model of Giftedness and Talent'. AGATE (Journal of the Gifted and Talented Education Council of the Alberta Teachers' Association), 11(1), 2-4.

Hoffman, J., Wasson, F. \& Christianson, B. (1985). 'Personal Development for the Gifted Underachiever'. Gifted Child Today, 8(3), 12-14. doi.org/ $10.1177 / 107621758500800305$

Levinson, D.J., Darrow, C.N., Klein, E.B., Levinson, M.H. \& McKee, B. (1978). The Seasons of A Man's Life. New York: Alfred A. Knopf.

Namadgi School. (2016). Gifted and Talented Policy. Retrieved from www.namadgi. act.edu.au/__data/assets/pdf_file/0007/362815/Gifted_and_Talented_ Education_at_Namadgi_School_POLICY.pdf

NSW State da Vinci Decathlon. (2015). Tasks and Solutions. Retrieved from: www. davincidecathlon.com/_literature_196775/2015_NSW_da_Vinci_Decathlon_ Tasks_and_Solutions_Years_9_and_10

Organisation for Economic Co-operation and Development (OECD). (2015). The ABC of Gender Equality in Education: Aptitude, Behaviour, Confidence. Programme for International Student Assessment, OECD Publishing.

Parliament of Victoria Education and Training Committee. (2012). Inquiry into the Education of Gifted and Talented Students. Retrieved from www.parliament. vic.gov.au/images/stories/committees/etc/Past_Inquiries/EGTS_Inquiry/Final_ Report/Gifted_and_Talented_Final_Report.pdf

Rea, D.W. (2000). 'Optimal Motivation for Talent Development'. Journal for the Education of the Gifted, 23(2), 187-216.

Reis, R.M. \& McCoach, B. (2000). 'The Underachievement of Gifted Students: What Do We Know and Where Do We Go?' Gifted Child Quarterly, 44(3), 152-170. doi.org/10.1177/001698620004400302 
Renzulli, J.S. (1977). The Enrichment Triad Model: A Guide for Developing Defensible Programs for the Gifted and Talented. Mansfield Center, CT: Creative Learning Press.

Renzulli, J.S. (1982). 'Dear Mr. and Mrs. Copernicus: We Regret to Inform You'. Gifted Child Quarterly, 26, 11-14. doi.org/10.1177/001698628202600103

Renzulli, J.S. (2012). 'Reexamining the Role of Gifted Education and Talent Development for the 21st Century: A Four Part Theoretical Approach'. Gifted Child Quarterly, 56(3), 150-159. doi.org/10.1177/0016986212444901

Torrance, E.P. (1980). 'Growing up Creatively Gifted: A 22-year Longitudinal Study'. Creative Child and Adult Quarterly, 5(1), 148-158.

Torrance, E.P. (1984). Mentor Relationships: How They Aid Creative Achievement, Endure, Change, and Die. Buffalo, NY: Bearly Limited. 
This text is taken from The ANU Undergraduate Research Journal, Volume Eight, 2016, edited by Daniel McKay, published 2017 by ANU eView, The Australian National University, Canberra, Australia.

dx.doi.org/10.22459/AURJ.08.2016.04 